\title{
Robot-Assisted Thoracic Surgery Versus Video-Assisted Thoracic Surgery for Lung Lobectomy or Segmentectomy in Patients With Non- Small Cell Lung Cancer: A Meta-Analysis
}

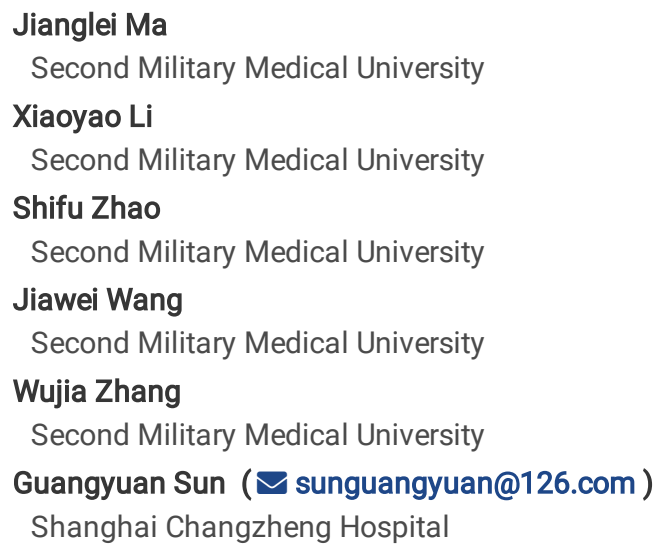

Keywords: Robot-assisted thoracic surgery, Video-assisted thoracic surgery, lobectomy, segmentectomy, non-small cell lung cancer Posted Date: February 1st, 2021

DOI: https://doi.org/10.21203/rs.3.rs-146301/v1

License: (c) (i) This work is licensed under a Creative Commons Attribution 4.0 International License. Read Full License 


\section{Abstract}

Background: It remains no clear conclusion about which is better between robot-assisted thoracic surgery (RATS) and video-assisted thoracic surgery (VATS) for the treatment of patients with non-small cell lung cancer (NSCLC). Therefore, this meta-analysis aimed to compare the shortterm and long-term efficacy between RATS and VATS for NSCLC.

Methods: Pubmed, Cochrane Library, Embase, China National Knowledge Infrastructure (CNKI), Medline and Web of Science databases were comprehensively searched for studies published before December 2020. The quality of the articles was evaluated using the Newcastle-Ottawa Scale (NOS) and the data analyzed using the Review Manager 5.3 software. Fixed or random effect models were applied according to heterogeneity. A sensitivity analysis was conducted. A funnel plot of the overall complication was used to assess the potential publication bias.

Results: A total of 18 studies including 11247 patients were included in the meta-analyses, of which 5114 patients were in the RATS group and 6133 in the VATS group. Compared with VATS, RATS was associated with less blood loss (WMD $=-50.40,95 \% \mathrm{Cl}-90.32 \sim-10.48, P=0.010$ ), lower conversion rate $(\mathrm{OR}=0.50,95 \% \mathrm{Cl} 0.43 \sim 0.60, P<0.001)$, more harvested lymph nodes $(\mathrm{WMD}=1.72,95 \% \mathrm{Cl} 0.63 \sim 2.81, P=0.002)$ and stations $(\mathrm{WMD}=0.51,95 \% \mathrm{Cl} 0.15 \sim 0.86, P=0.005)$, shorter duration of postoperative chest tube drainage (WMD $=-0.61,95 \% \mathrm{Cl}-0.78 \sim-0.44, P<0.001)$ and hospital stay (WMD $=-1.12,95 \% \mathrm{Cl}-1.58 \sim-0.66, P<0.001)$, lower overall complication rate $(\mathrm{OR}=0.90,95 \% \mathrm{Cl} 0.83 \sim 0.99, P=0.020)$, and lower recurrence rate $(\mathrm{OR}=0.51,95 \% \mathrm{Cl} 0.36 \sim 0.72, P<0.001)$. There was no significant difference between RATS and VATS in operative time, mortality, overall survival (OS), and disease-free survival (DFS). Sensitivity analysis showed that no significant differences were found between the two techniques in conversion rate, number of harvested lymph nodes and stations, and overall complication.

Conclusions: The results revealed that RATS is a feasible and safe technique compared with VATS in terms of short and long term outcomes. Moreover, more randomized controlled trials comparing the two techniques with rigorous study designs are still essential to evaluate the value of the robotic surgery for NSCLC.

\section{Introduction}

At present, lung cancer is still the leading cause of cancer morbidity and mortality worldwide, with NSCLC accounting for $80-85 \%$ of all lung cancer cases [1, 2]. Surgical resection, including traditional thoracotomy and minimally invasive surgery (MIS), is still the current preferred treatment for lung cancer, and surgical resection with lymphadenectomy is considered to be the standard treatment for patients with NSCLC at an early stage [3, 4]. Since the initial VATS lobectomy was first performed in the early 1990s, VATS has been widely used in thoracic surgery all over the world, and its safety and effectiveness in the treatment of early NSCLC have been confirmed, which makes it become the main surgical procedure for lung cancer resection [5-8].

In recent years, VATS has been recognized for its advantages of MIS in the treatment of NSCLC, such as less blood loss, less postoperative pain, fewer complications, faster recovery, shorter hospital stay and lower mortality rates [9-10]. Clinical trials comparing VATS with conventional thoracotomy have shown that VATS has superior perioperative outcomes and improved long-term survival [11-12]. Although VATS has such advantages, it has also limitations of itself, including two-dimensional vision, difficult handeye coordination, amplification of hand tremor, steep learning curve, lack of flexibility and limited ranges of instrument movement, which may restrict the development of this technique [13-14].

Advantages of RATS include high definition three-dimensional stereo video, improved ergonomics less steep learning curve, tremor suppression and better maneuverability of instruments, which can promote complex movements in a closed space and influence the perioperative outcomes [15-17]. Da Vinci robot, currently the latest generation of robotic surgery systems in the world, has unlocked a new era of MIS and been widely used in urinary tract, cardiovascular, hepatobiliary, gastrointestinal and gynecological surgery [18]. Since Melfi et al. [19] firstly applied it to lung surgery in 2002, studies on RATS have been widely reported.

Many researches published in the past 10 years have confirmed the feasibility and safety of RATS, which are meaningful in highlighting the status of RATS in the treatment of NSCLC [20-22]. However, these researches included single-center studies with the small simple size and different appraise systems of complications, which limited them to conclude objective result. Moreover, RATS may be restricted by its higher hospital costs and longer operative time. Therefore, there is no clear conclusion whether RATS can achieve an equal or even better surgical effect when compared with VATS. We conducted this meta-analysis to explore and compare the short-term and long-term outcomes of RATS versus VATS for lung lobectomy or segmentectomy in patients with NSCLC.

\section{Methods}

\section{Search Strategy}

The Preferred Reporting Items for Systematic Reviews and Meta-Analyses (PRISMA) statement was applied to perform this study and the PRISMA checklist was completed [23]. A systematic literature search was performed in Pubmed, Cochrane Library, Embase, CNKI, Medline and Web of Science for studies published before December 2020 that assessed the comparison between RATS and VATS in the treatment of NSCLC, using the 
following searching terms: "robot-assisted OR robot-assisted thoracic surgery OR robot OR robotic OR computer-assisted surgery OR da Vinci", "video-assisted OR video-assisted thoracic surgery OR video OR thoracoscopic", "lung lobectomy OR segmentectomy", and "non-small cell lung cancer OR lung cancer OR lung carcinoma". In addition, the reference lists of all relevant articles were also searched to identify the additional relevant literature. There was no restriction on the language of the articles.

\section{Inclusion criteria and Exclusion criteria}

The included studies must meet the following criteria: (1) Clinical studies comparing RATS with VATS for lung lobectomy or segmentectomy in patients with NSCLC; (2) Full-text articles that reported necessary data for statistical analysis, including at least one of the following outcomes: operative time, estimated blood loss, conversion, the number of dissected lymph nodes, length of hospital stay, postoperative duration of drainage, postoperative complications, mortality, OS, DFS, and recurrence rate; (3) If the same team or institution reported more than one studies, the latest, the larger scale number or high quality publication were included. If two or more studies contained totally different cases from the same center, we still analyzed the data from these studies.

Articles were excluded if they met any of the following criteria: (1) Case reports, review articles, animal experimental studies, letters to the editor, meeting abstracts, comments, and other non-related studies; (2) Studies including other cases such as benign lung diseases; (3) Studies without necessary data for statistical analysis.

\section{Data extraction and quality assessment of included studies}

Two reviewers independently extracted the data from all included researches and examined the results again carefully. If there were discrepancies, the controversial results were resolved by group discussion, and a final decision was made by a senior investigator. The following data were collected: first author, publication year, country, study design, sample size (RATS group and VATS group), mean age, sex, surgical techniques, tumor site, TNM stage, operative time, estimated blood loss, conversion, the number of dissected lymph nodes and stations, length of hospital stay, postoperative duration of drainage, postoperative complications, mortality, OS, DFS, and recurrence rate. If the research reported medians and ranges, the means and standard deviations (SD) were calculated according to the method described by Hozo et al. [24]. The NOS was used to assess the quality of included studies. Scores range from 0 to 9 stars: studies with a score more than or equal to 7 were premeditated to be highquality and included in the meta-analysis.

\section{Sensitivity analysis}

Abraham et al. [25] proved that when comparing the short-term outcomes of surgery, the results obtained by combining high-quality nonrandomized controlled trials were also convincing. To determine whether the pooled results are robust and reliable, a sensitivity analysis will be performed by excluding the studies with the lowest-quality score.

\section{Statistical analysis}

All statistical analyses were performed using the Review Manager 5.3 software (Cochrane Collaboration, Oxford, UK). The dichotomous variables were assessed by using odds ratios (OR) with a 95\% confidence interval (CI) and the continuous variables using weighted mean difference (WMD) with a $95 \% \mathrm{Cl}$. The hazard ratio (HR) with its corresponding $95 \% \mathrm{Cl}$ was utilized to assess the survival data such as OS and DFS. The $P$ statistics was used to evaluate the heterogeneity. $R^{2}<25 \%, 25 \% \leq R^{2} \leq 50 \%$ and $R^{2}>50 \%$ were considered to be low, moderate, and high heterogeneity, respectively. If the test of heterogeneity was high $(R>50 \%$ or $P<0.05)$, a random-effect model was adopted. Otherwise, we used a fix effect model. The potential publication bias was evaluated by visually inspecting the funnel plots. $P<0.05$ was regarded as statistically significant.

\section{Results}

\section{Selected studies}

A total of 2829 potential articles published before December 2020 were found from databases. After duplicates were removed, 1872 articles were initially evaluated by carefully reading the titles and abstracts, of which 1708 studies were excluded because they were review articles, case reports, animal experimental studies, letters, meeting abstracts, comments and other non-related studies. 164 potential articles were further assessed through reading the full texts, and finally, according to inclusion and exclusion criteria, a total of 18 retrospective studies were included in the final meta-analysis [26-43]. The flow chart of the screening strategies, which contains reasons for the exclusion of studies, is depicted in Fig. 1.

\section{Study characteristics and quality}

A total of 18 studies with 11247 patients, of whom 5114 patients were in the RATS group and 6133 in the VAST group, were involved in the analysis. Five included studies were published in Chinese [30,31,35-37], and 13 were published in English [26-29,32-34,38-43]. Among the 18 studies, 11 studies were from China [27,30,31,33-37,39,41,42], 6 from the USA [26,28,29,32,38,43] and 1 from Japan [40]. The basic characteristics 
of the included studies are listed in Table 1. The quality assessment of the included studies according to the NOS is elucidated in Table 2. It showed that 9 of the 18 included studies had 7 stars [27,28,31-33,35-37,41], 4 had 8 stars [26,30,34,42], and 5 had 9 stars [29,38-40,43]. 


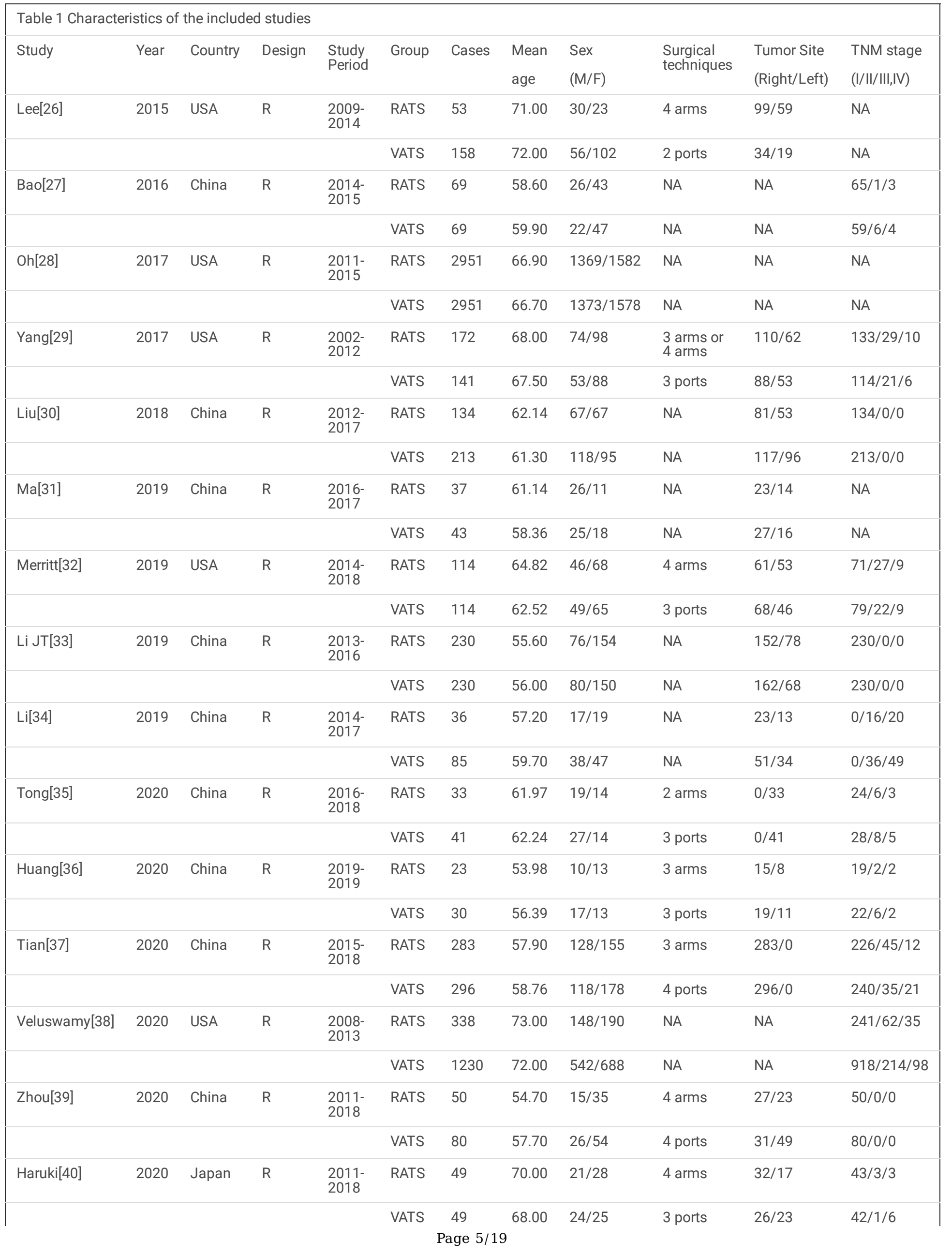




\begin{tabular}{|c|c|c|c|c|c|c|c|c|c|c|c|}
\hline Zhang[41] & 2020 & China & $\mathrm{R}$ & $\begin{array}{l}2015- \\
2019\end{array}$ & RATS & 257 & 53.53 & $84 / 173$ & 4 arms & $127 / 130$ & NA \\
\hline & & & & & VATS & 257 & 52.21 & $89 / 168$ & NA & $124 / 133$ & NA \\
\hline \multirow[t]{2}{*}{ Qiu[42] } & 2020 & China & $\mathrm{R}$ & $\begin{array}{l}2012- \\
2017\end{array}$ & RATS & 40 & 61.40 & $36 / 4$ & $3 \mathrm{arms}$ & $24 / 16$ & NA \\
\hline & & & & & VATS & 38 & 61.70 & $34 / 4$ & $\begin{array}{l}2 \text { ports or } \\
3 \text { ports }\end{array}$ & $17 / 21$ & NA \\
\hline \multirow[t]{2}{*}{ Kneuertz[43] } & 2020 & USA & $\mathrm{R}$ & $\begin{array}{l}2012- \\
2017\end{array}$ & RATS & 245 & 65.30 & $47 / 53$ & 4 arms & $61 / 40$ & $86 / 10 / 5$ \\
\hline & & & & & VATS & 118 & 64.60 & $45 / 55$ & 4 ports & $58 / 42$ & $90 / 6 / 4$ \\
\hline
\end{tabular}

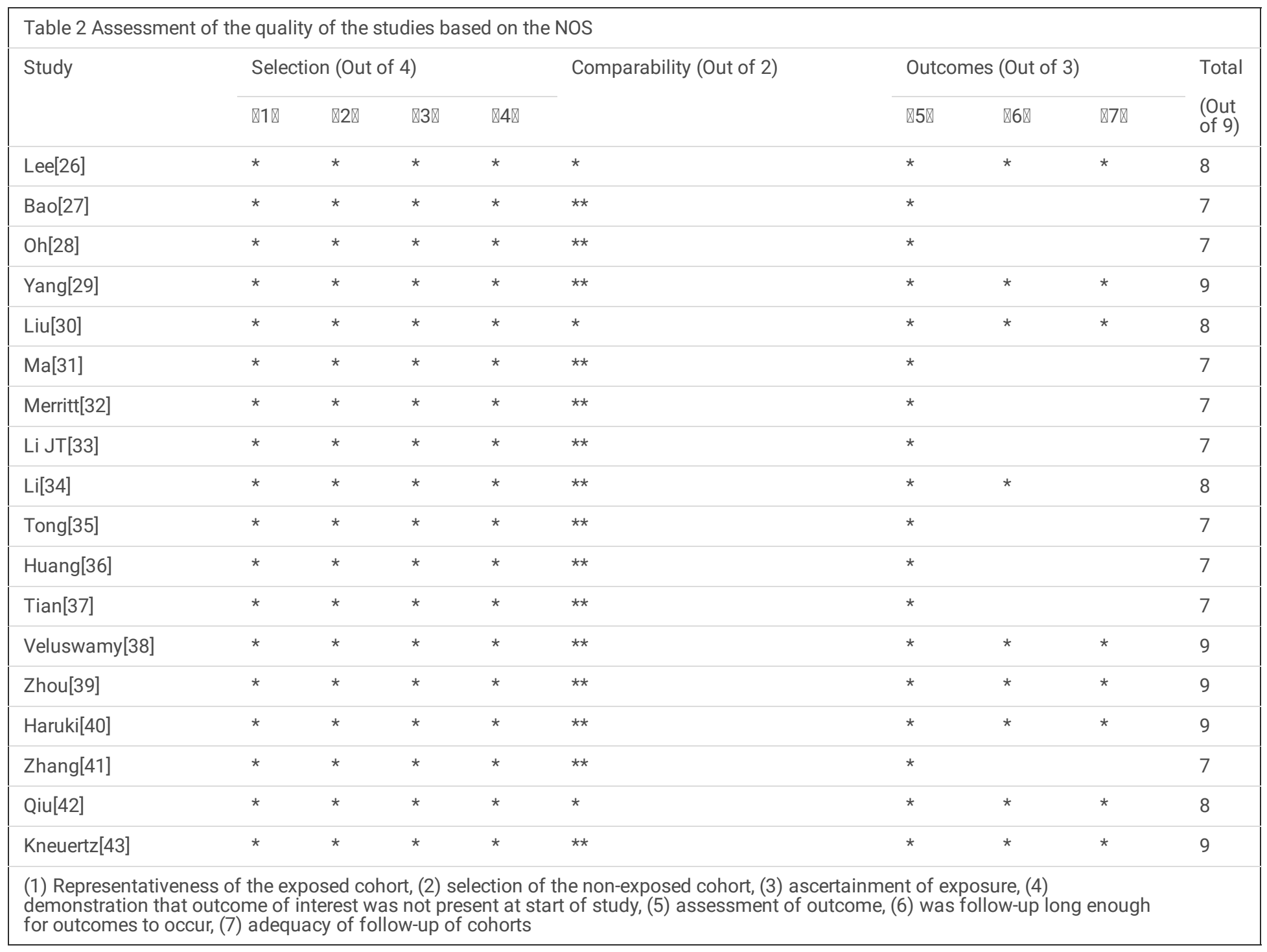

\section{Short-term outcomes}

All results of meta-analysis for short-term outcomes are shown in Fig. 2, Fig. 3 and Fig. 4, which are summarized in Table 3. Thirteen studies reported the operative time. Because of significant heterogeneity $(R=97 \%, P<0.001)$, a random effect model was adopted. The pooled data based on 13 studies revealed no significant difference between the groups of RATS and VATS (WMD $=-0.79,95 \% \mathrm{Cl}-15.65 \sim 14.06, P=0.920)$ (Fig. 2a). The EBL was reported in 7 studies. Because there was significant heterogeneity between the 7 studies $(R=93 \%, P<0.001)$, a random-effect model was used. Pooled analysis of the data showed that the EBL was less in RATS than VATS (WMD $=-50.40,95 \% \mathrm{Cl}-90.32 \sim-10.48, P=0.010)(F i g .2 b)$. 
The data regarding the conversion cases were reported in 12 studies. Because of the lack of high heterogeneity $(R=37 \%, P=0.100)$, a fixed effect model was adopted. Meta-analysis showed that the conversion rate of RATS group was lower than that of VATS group (OR $=0.50,95 \% \mathrm{Cl}$

$0.43 \sim 0.60, P<0.001$ ) (Fig. 2c).

Eight studies reported the number of dissected lymph nodes stations. The pooled results showed that the number of dissected lymph nodes stations was more in RATS than VATS (WMD $=0.51,95 \% \mathrm{Cl} 0.15 \sim 0.86, P=0.005)$ (Fig. 3a), with a high heterogeneity $(P=86 \%, P<0.001)$, which made a random effect model adopted. The number of dissected lymph nodes was described in 14 studies. Significant heterogeneity was observed in the 14 studies $\left(P^{2}=93 \%, P<0.001\right)$, so a random effect model was adopted. Pooled analysis showed that the number of dissected lymph nodes of RATS group was more than that of VATS group (WMD $=1.72,95 \% \mathrm{Cl} 0.63 \sim 2.81, P=0.002)$ (Fig. 3b).

The time of chest tube drainage was reported in 9 studies. Pooled analysis of the data showed that the time of chest tube drainage was shorter in RATS than VATS (WMD $=-0.61,95 \% \mathrm{Cl}-0.78 \sim-0.44, P<0.001)$ (Fig. 4a). The pooled result was measured using a fixed effect model due to the lack of high heterogeneity $(R=37 \%, P=0.120)$. Fourteen studies reported the length of hospital stay. A random effect model was adopted because of significant heterogeneity $\left(P^{2}=80 \%, P<0.001\right)$. The result of pooled analysis revealed that the length of hospital stay was shorter in RATS than that of VATS (WMD $=-1.12,95 \% \mathrm{Cl}-1.58 \sim-0.66, P<0.001$ ) (Fig. 4b). Fifteen studies including a total of 10619 patients presented the overall postoperative complication and a fixed effect model was used due to no significant heterogeneity $(P=11 \%, P=0.330)$. Pooled analysis showed that the rate of overall postoperative complication was lower in RATS than VATS (OR $=0.90,95 \% \mathrm{Cl} 0.83 \sim 0.99, P=0.020)($ Fig. $4 \mathrm{C}$ ). Moreover, six studies reported the postoperative mortality and no significant difference was identified between the two groups (OR $=0.99,95 \% \mathrm{Cl} 0.68 \sim 1.45, P=$ 0.970 ) (Fig. 4d), with no significant heterogeneity $\left({ }^{2}=37 \%, P=0.160\right)$, which made a fixed effect model used.

\section{Long-term outcomes}

All results of meta-analysis for long-term outcomes are shown in Fig. 5, which are outlined in Table 3 . Four studies described the OS and no significant difference could be found in OS between the two techniques ( $\mathrm{HR}=1.02,95 \% \mathrm{Cl} 0.82 \sim 1.26, P=0.880)$ (Fig. 5a). Because of the lack of significant heterogeneity $\left({ }^{2}=28 \%, P=0.240\right)$, a fixed effect model was adopted. The DFS outcomes were recorded in 2 studies. Pooled analysis showed no significant heterogeneity $\left(R^{2}=0 \%, P=0.490\right)$, which made a fixed effect model adopted. The pooled results indicated that the DFS outcomes were similar between the two groups ( $\mathrm{HR}=1.03,95 \% \mathrm{Cl} 0.66 \sim 1.61, P=0.890)$ (Fig. $5 \mathrm{~b}$ ). Cancer recurrence was reported in six studies and the pooled data indicated that the recurrence rate of RATS was lower than that of VATS (OR $=0.51,95 \% \mathrm{CI} 0.36 \sim 0.72, P<0.001)$. A fixed effect model was used due to the lack of high heterogeneity $\left({ }^{2}=0 \%, P=0.490\right)$ (Fig. 5c).

\begin{tabular}{|c|c|c|c|c|c|c|c|c|}
\hline \multicolumn{9}{|c|}{ Table 3 Results of the meta-analysis } \\
\hline \multirow[t]{2}{*}{ Outcomes } & \multirow{2}{*}{$\begin{array}{l}\text { No. of } \\
\text { studies }\end{array}$} & \multicolumn{2}{|c|}{ Sample size } & \multicolumn{2}{|c|}{ Heterogeneity } & \multirow{2}{*}{$\begin{array}{l}\text { Overall effect } \\
\text { size }\end{array}$} & \multirow{2}{*}{$\begin{array}{l}95 \% \mathrm{Cl} \text { of overall } \\
\text { effect }\end{array}$} & \multirow{2}{*}{$\begin{array}{l}\mathrm{P} \\
\text { Value }\end{array}$} \\
\hline & & RATS & VATS & $I^{2} \rrbracket \% \bigotimes$ & $\begin{array}{l}\mathrm{P} \\
\text { Value }\end{array}$ & & & \\
\hline Operation time (min) & 13 & 3995 & 4211 & 97 & $<0.001$ & WMD $=-0.79$ & $-15.65 \sim 14.06$ & 0.920 \\
\hline Estimated blood loss (mL) & 7 & 385 & 483 & 93 & $<0.001$ & WMD $=-50.40$ & $-90.32 \sim-10.48$ & 0.010 \\
\hline Conversion & 12 & 4441 & 4461 & 37 & 0.100 & $\mathrm{OR}=0.50$ & $0.43 \sim 0.60$ & $<0.001$ \\
\hline Dissected lymph node stations & 8 & 997 & 1144 & 86 & $<0.001$ & WMD $=0.51$ & $0.15 \sim 0.86$ & 0.005 \\
\hline Dissected lymph nodes & 14 & 1396 & 1564 & 93 & $<0.001$ & WMD =1.72 & $0.63 \sim 2.81$ & 0.002 \\
\hline $\begin{array}{l}\text { Time of chest tube drainage } \\
\text { (days) }\end{array}$ & 9 & 892 & 1075 & 37 & 0.120 & WMD =-0.61 & $-0.78 \sim-0.44$ & $<0.001$ \\
\hline Length of hospital stay (days) & 14 & 4225 & 4489 & 80 & $<0.001$ & WMD $=-1.12$ & $-1.58 \sim-0.66$ & $<0.001$ \\
\hline Overall complications & 15 & 4890 & 5729 & 11 & 0.330 & $\mathrm{OR}=0.90$ & $0.83 \sim 0.99$ & 0.020 \\
\hline Mortality & 6 & 3623 & 4587 & 37 & 0.160 & $\mathrm{OR}=0.99$ & $0.68 \sim 1.45$ & 0.970 \\
\hline Overall survival & 4 & 659 & 1471 & 28 & 0.240 & $H R=1.02$ & $0.82 \sim 1.26$ & 0.880 \\
\hline Disease-free survival & 2 & 76 & 123 & 0 & 0.490 & $H R=1.03$ & $0.66 \sim 1.61$ & 0.890 \\
\hline Recurrence rate & 6 & 605 & 631 & 0 & 0.490 & $\mathrm{OR}=0.51$ & $0.36 \sim 0.72$ & $<0.001$ \\
\hline
\end{tabular}

\section{Sensitivity analysis}


We performed a sensitivity analysis for high-quality studies with more than 7 stars. The results of the sensitivity analysis showed that there were no significant difference between RATS and VATS on conversion rate (OR $=0.97,95 \% \mathrm{Cl} 0.55 \sim 1.73, P=0.930, P=0 \%$ ) (Fig. $6 \mathrm{a})$, the number of dissected lymph node stations (WMD $=0.49,95 \% \mathrm{Cl}-0.25 \sim 1.22, P=0.190, P^{2}=90 \%$ ) (Fig. 6b), the number of dissected lymph nodes (WMD $=2.22$, $95 \% \mathrm{Cl}-0.33 \sim 4.77, P=0.090, P=94 \%$ ) (Fig. $6 \mathrm{c})$, and the rate of overall postoperative complication $(\mathrm{OR}=1.01,95 \% \mathrm{Cl} 0.82 \sim 1.24, P=0.940, P=$ $20 \%$ ) (Fig. 6d), but the tendency was not changed. Compared with the overall outcomes, no significant changes were found in the remaining results. The results are shown in the Supplementary.

\section{Publication of bias}

A funnel plot of the overall complication was used to assess publication bias. The bilaterally symmetrical funnel plot of overall complication showed that no obvious evidence of publication bias was observed (Fig. 7).

\section{Discussion}

Radical resection with lymphadenectomy is regarded as gold standard surgical approach of treatment for patients with NSCLC at an early stage [4, 37]. As numerous researchers have proven its safety and effectiveness, MIS used to treat early stage NSCLC has rapidly spread during the past decade. Minimally invasive VATS has been suggested for resection of NSCLC as a consequence of the improved short outcomes, such as shorter length of chest tube duration, lower rates of complications, and reduced length of stay, while maintaining an equivalent long-term survival rate compared to open thoracotomy [44]. Many studies have compared the safety and short or long term efficacy of VATS with open thoracotomy, but studies on RATS have not been sufficient to prove its benefits. Therefore, we included 18 studies and conducted a meta-analysis to explore and compare the clinical efficacy of RATS and VATS.

Regarding the operative time, the result of meta-analysis revealed that the operative time was similar between the two groups, with no statistical difference, which was consistent with the results reported by Liang et al. [45]. However, most previous studies reported a longer operative time for RATS compared to VATS, which was contrary to our results [26, 46-48]. The main reason might come from the difference of the experience of surgeons. Previous researches just reported their initial attempts to RATS for lung cancer and the experience and knowledge of RATS for surgeons were inadequate at the beginning of the learning curve, which might contribute to longer operative time. In our included studies, some surgeons had proficient operation experience in thoracoscopic lung cancer resection, which made the learning curve for robot-assisted lung cancer resection shorter and shortened the operative time significantly. Zhou et al. [39] described that the RATS group showed a sharper concurrent reduction in operation time than that for VATS after the surgeons performing RATS had obtained more than ten years of advanced experience in performing VATS procedures. Merritt et al. [32] reported that the mean operative time for the final 20 RATS procedures was significantly shorter than that of the first 20 RATS procedures. Therefore, with the increased experience of RATS, operative time for RATS would be comparable to VATS.

Intraoperative blood loss mainly occurs during lymph node dissection, which is caused by vascular damage. Analysis of the pooled data showed that the blood loss was lower in RATS than VATS. The reason may be that RATS provides a three-dimensional magnified vision and more flexible equipments, eliminates hand tremors and accurately reveals the complex anatomy around the mediastinum and hilar, which helps surgeons perform precise manipulation and better control bleeding in small blood vessels [31]. In terms of the conversion rate, the results of this metaanalysis suggested that the conversion rate of RATS group was lower than that of VATS, but this was not consistent with the result of sensitivity analysis. Although no significant difference could be found in the conversion rate between the two techniques according to the result of sensitivity analysis, the pooled result revealed that VATS group still had a higher conversion rate than RATS group.

Lymph node dissection is an important factor affecting the prognosis of NSCLC. Previous studies showed that there was no significant difference between RATS and VATS in the number of dissected lymph nodes and stations [33,49]. Meanwhile, there were also studies that revealed that RATS could achieve more lymph node dissections than VATS $[50,51]$. The results of this study were also more inclined to the latter. The mediastinum and hilar lymph nodes are relatively deep, and the adjacent anatomy is complicated. Therefore, the dissection of the mediastinum and hilar lymph nodes has always been a major test for the technique of the surgeons and the flexibility of surgical instruments [52]. The robotic surgery system has an internal articulated EndoWrist with $7^{\circ}$ of freedom, which makes it more accurate than VATS in the separation of deep tissues and the removal of lymph nodes in complex anatomical locations. Postoperative pathological lymph node upstaging can better reflect the thoroughness of lymph node dissection. Wilson et al. [53] and Kneuertz et al. [54] reported a rate of lymph node upstaging for robotic resection appeared to be superior to VATS, which indicated that the lymph node dissection of RATS was more thorough. However, after we conducted a sensitivity analysis, the results showed that there was no significant difference in the number of dissected lymph nodes and stations. Nevertheless, these could at least show that robotic surgery could achieve similar results with VATS.

In this study, the duration of postoperative chest tube drainage and hospital stay of patients in the RATS group were shorter than those in the VATS group, which was similar to the results of other studies $[35,55]$. The possible reason is that the robotic surgery system has many minimally invasive advantages, which make the operation more delicate, more thorough hemostasis, less irritation to surrounding tissues such as pleura, resulting in less pleural effusion and saving the duration of postoperative drainage. In addition, patients recovered faster after surgery, which also shortened the postoperative hospital stay to a certain extent [56]. 
The incidence of postoperative complications is an important indicator for evaluating the short-term outcomes. The pooled result of meta-analysis indicated that the postoperative complication rate in the group of RATS was less than in VATS group. It might be related to the continuous advancement of robotic surgery system and the improvement of the proficiency of surgeons in its operation, which made robotic surgery less harmful to patients and fewer postoperative complications [57]. However, the result of sensitivity analysis showed that there was no significant difference in the postoperative complication rate between the two groups,therefore, this result should be interpreted with caution. Further prospective randomized controlled studies are needed in order to confirm the advantage. In terms of the mortality, analysis of the pooled data indicated that the mortality of the RATS group was similar to that of the VATS group, which was inconsistent with the result reported in previous study that the mortality of RATS was significantly reduced compared with VATS [58]. It might be related to the highly selected patients at the beginning of this surgical technique. Sensitivity analysis also showed that there was no difference in mortality between the two techniques, which suggested that our result was robust and reliable. According to these results, we believe that RATS is safe and acceptable.

Because lung cancer is a malignant tumor, the long-term survival outcomes of patients with NSCLC requires special attention from the surgeons. As far as we know, our study analyzed the long-term survival outcomes of RATS and VATS for the first time. In our study, OS, a major oncologic outcome, was similar between the two groups. Pooled analysis showed no significant difference between the RATS and VATS groups in DFS, without significant heterogeneity. Regarding the recurrence rate, meta-analysis showed that it was significantly lower in RATS than VATS.

According to the description of previous studies, tumor size, resection margin, lymph node dissection and time of follow-up were considered to be some of the factors influencing the postoperative recurrence of patients with NSCLC [59, 60]. One of the included studies reported that no local recurrence or distant recurrence appeared in the RATS group within the median 38-month follow-up time, while the local recurrence and distant recurrence rate in the VATS group was $2.5 \%$ and 3.75\% respectively during a median follow-up time of 85 months [39]. Moreover, Li et al. [34] reported that the recurrence rate was $52.8 \%$ in the RATS group and $54.1 \%$ in the VATS group during a median follow-up length of 33.9 months. The above all indicated that the long-term oncologic outcomes of RATS might be slightly better than VATS and confirmed that RATS is a feasible and safe technique for the management of NSCLC. However, multi-center and large-scale clinical randomized controlled trials are needed to verify these results to provide more reliable evidence.

The possible limitations of our study must be considered when applying these results in the clinic. First, all studies included for meta-analysis were retrospective observational studies and lacked high-quality randomized controlled trials, with a greater risk of potential selection and publication bias, which might influence the quality of meta-analysis. However, no significant publication bias was observed in our study. Second, we found that the operative time, blood loss, number of dissected lymph nodes and stations,and postoperative hospital stay had significant heterogeneity although the heterogeneity of other outcomes was not significant. Potential factors that could explain the heterogeneity included the different experience of surgeons and the shorter learning curve for the robotic group. Third, the median, SD, HR, and standard error (SE) were not directly reported in some studies. The median and SD were calculated according to the methods described in previous studies, while HR and SE were extracted from the survival curves, which might result a potential source of bias. Finally, our meta-analysis did not assess the cost effectiveness of RATS compared with VATS. However, based on the results of most previous studies, RATS is more expensive than VATS.

\section{Conclusion}

In conclusion, our meta-analysis suggested that RATS is a feasible and safe technique that can achieve the same or even better surgical efficacy compared with VATS in terms of short-term and long-term outcomes. RATS makes up for the limitations of VATS in treatment of NSCLC, which can make patients have fewer trauma and quicker recovery. However, large sample and high quality randomized clinical trials are still essential to compare RATS with VATS to better demonstrate the potential advantages and disadvantages of both of the minimally invasive approaches for NSCLC.

\section{Abbreviations List}

Cl:confidence interval

$\mathrm{CNKI}$ :china national knowledge infrastructure

DFS『disease-free survival

EBL:estimated blood loss

F:female

HR:hazard ratios

M:male

MIS:minimally invasive surgery 
NA:not available

NOS:Newcastle-Ottawa Scale

NSCLC『non-small cell lung cancer

OR:odds ratios

OS:overall survival

PRISMA:Preferred Reporting Items for Systematic Reviews and Meta-Analyses

R:retrospective

RATS:robot-assisted thoracic surgery

SD:standard deviation

SE:standard error

VATS $₫$ video-assisted thoracic surgery

WMD:weighted mean difference

\section{Declarations}

Ethics approval and consent to participate The study did not need ethics approval.

Consent for publication Not applicable

Availability of data and materials All data generated or analysed during this study are included in this published article and its supplementary information files.

Competing interests The authors declare that they have no competing interests.

Funding Not applicable

Authors' contributions JM and XL wrote the manuscript. SZ performed the data search and data analysis. JW and WZ performed the data search. GS performed the study design. All authors corrected and proofed the final text. All authors read and approved the final manuscript.

Acknowledgements Not applicable

Authors' information ${ }^{1}$ Student of the College of Basic Medical Sciences, Naval Medical University,Shanghai 200433, China. ${ }^{2}$ Department of Thoracic Surgery, Changzheng Hospital, Naval Medical University, Shanghai 200003, China.

\section{References}

1. Bray F, Ferlay J, Soerjomataram I, et al. Global cancer statistics 2018: GLOBOCAN estimates of incidence and mortality worldwide for 36 cancers in 185 countries. CA Cancer J Clin. 2018;68:394-424.

2. Zappa C, Mousa SA. Non-small cell lung cancer: current treatment and future advances. Transl Lung Cancer Res. 2016;5:288-300.

3. Xie BH, Sui TY, Qin Y, et al. Comparison of Short-term Outcomes of Lung Segmentectomy by Robotic-assisted and Video-assisted Thoracoscopic Surgery. Zhong Guo Fei Ai Za Zhi. 2019;22:767-771.

4. Ginsberg RJ, Rubinstein LV. Randomized trial of lobectomy versus limited resection for T1 NO non-small cell lung cancer. Lung Cancer Study Group. Ann Thorac Surg. 1995;60:615-622.

5. Kirby TJ, Mack MJ, Landreneau RJ, et al. Initial experience with videoassisted thoracoscopic lobectomy. Ann Thorac Surg. 1993;56:1248-52.

6. Walker WS, Carnochan FM, Pugh GC. Thoracoscopic pulmonary lobectomy. Early operative experience and preliminary clinical results. J Thorac Cardiovasc Surg. 1993;106:1111-7.

7. Jawitz OK, Wang Z, Boffa DJ, et al. The differential impact of preoperative comorbidity on perioperative outcomes following thoracoscopic and open lobectomies. Eur J Cardiothorac Surg Off J Eur Assoc Cardiothorac Surg. 2017;51:169-74.

8. Mathisen DJ. Re: video-assisted thoracoscopic surgery versus open lobectomy for primary non-small-cell lung cancer: a propensity-matched analysis of outcome from the European Society of Thoracic Surgeon database. Eur J Cardiothorac Surg Off J Eur Assoc Cardiothorac Surg.

Page $10 / 19$ 
2016;49:609-10.

9. Ghaly G, Kamel M, Nasar A, et al. Video-assisted thoracoscopic surgery is a safe and effective alternative to thoracotomy for anatomical segmentectomy in patients with clinical stage I non-small cell lung cancer. Ann Thorac Surg. 2016;101:465-72

10. Tsubokawa N, Harada H, Takenaka C, et al. Comparison of postoperative pain after different thoracic surgery approaches as measured by electrical stimulation. Thorac Cardiovasc Surg. 2015;63:519-25.

11. Nwogu CE, D'Cunha J, Pang H, et al. VATS lobectomy has better perioperative outcomes than open lobectomy: CALGB 31001 , an ancillary analysis of CALGB 140202 (Alliance). Ann Thorac Surg. 2015;99:399-405.

12. Cao C, Zhu ZH, Yan TD, et al. Video-assisted thoracic surgery versus open thoracotomy for non-small-cell lung cancer: a propensity score analysis based on a multi-institutional registry. Eur J Cardiothorac Surg. 2013;44:849-854.

13. Velez-Cubian FO, Ng EP, Fontaine JP, et al. Robotic-Assisted Videothoracoscopic Surgery of the Lung. Cancer Contro.I 2015;22:314-25.

14. Arad T, Levi-Faber D, Nir RR, et al. The learning curve of video-assisted thoracoscopic surgery (VATS) for lung lobectomy: a single Israeli center experience. Harefuah. 2012;151:261-5.

15. Veronesi G, Novellis P, Voulaz E, et al. Robot-assisted surgery for lung cancer: State of the art and perspectives. Lung Cancer. 2016;101:28-34.

16. Soliman BG, Nguyen DT, Chan EY, et al. Impact of da Vinci Xi robot in pulmonary resection. J Thorac Dis. 2020;12:3561-3572.

17. Ahn S, Jeong JY, Kim HW, et al. Robotic lobectomy for lung cancer: initial experience of a single institution in Korea. Ann Cardiothorac Surg. 2019;8:226-232.

18. Liu GX, Shen WS, Chen L, et al. Robotic versus laparoscopic gastrectomy for gastric cancer囚a meta-analysis. Zhong Hua Wei Chang Wai Ke Za Zhi. 2016;19:328-333.

19. Melfi FM, Menconi GF, Mariani AM, et al. Early experience with 18 robotic technology forthoracoscopic surgery. Eur J Cardiothorac Surg. 2002;21: 864-868.

20. Nelson DB, Mehran RJ, Mitchell KG, et al. Robotic Assisted Lobectomy For Non-Small Cell Lung Cancer: A Comprehensive Institutional Experience. Ann Thorac Surg.2019;108:370-376.

21. Kneuertz PJ, Singer E, D'Souza DM et al. Hospital cost and clinical effectiveness of robotic-assisted versus video-assisted thoracoscopic and open lobectomy: A propensity score-weighted comparison. J Thorac Cardiovasc Surg. 2019;157:2018-26.

22. Pierluigi N, Edoardo B, Emanuele V, et al. Robotic surgery, video-assisted thoracic surgery, and open surgery for early stage lung cancer: comparison of costs and outcomes at a single institute. J Thorac Dis. 2018;10:790-798.

23. Moher D, Liberati A, Tetzlaff J, et al. Preferred reporting items for systematic reviews and meta-analyses: the PRISMA statement. Int J Surg. 2010;8:336-41.

24. Hozo SP, Djulbegovic B, Hozo I. Estimating the mean and variance from the median, range, and the size of a sample.BMC medical research methodology. 2005;5:13.

25. Abraham NS, Byrne CJ, Young JM, et al. Meta-analysis of welldesigned nonrandomized comparative studies of surgical procedures is as good as randomized controlled trials. J Clin Epidemiol.2010;63:238-245.

26. Lee BE, Shapiro M, Rutledge JR, et al. Nodal Upstaging in Robotic and Video Assisted Thoracic Surgery Lobectomy for Clinical NO Lung Cancer. The Society of Thoracic Surgeons.2015;100:229-234.

27. Bao FC, Zhang C, Yang YH, et al.Comparison of robotic and video-assisted thoracic surgery for lung cancer: a propensity-matched analysis.J Thorac Dis.2016;8:1798-803.

28. Oh DS, Reddy RM, Gorrepati ML, et al. Robotic-Assisted, Video-Assisted Thoracoscopic and Open Lobectomy: Propensity-Matched Analysis of Recent Premier Data.The Society of Thoracic Surgeons. 2017;104:1733-1740.

29. Yang HX, Woo KM, Sima CS, et al. Long-term Survival Based on the Surgical Approach to Lobectomy For Clinical Stage I Nonsmall Cell Lung Cancer: Comparison of Robotic, Video-assisted Thoracic Surgery, and Thoracotomy Lobectomy. Ann Surg. 2017; 265:431-437.

30. Liu XC, Xu SG, Liu B, et al. Survival Analysis of Stage I Non-small Cell Lung Cancer Patients Treated with Da Vinci Robot-assisted Thoracic Surgery.Department of Thoracic Surgery. 2018; 21:849-856.

31. Ma JL, Jin DC, Han SC, et al.Robot-assisted thoracic surgery versus video-assisted thoracic surgery for early-stage lung cancer: A case control study.Chinese J Clin Thorac Cardiovasc Surg.2019;26:48-52.

32. Merritt RE, Kneuertz PJ, D'Souza DM. Successful Transition to Robotic-Assisted Lobectomy With Previous Proficiency in Thoracoscopic Lobectomy. Innovations.2019;14:263-271.

33. Li JT, Liu PY, Huang J, et al. Perioperative outcomes of radical lobectomies using robotic-assisted thoracoscopic technique vs. video-assisted thoracoscopic technique: retrospective study of 1,075 consecutive p-stage I non-small cell lung cancer cases. J Thorac Dis. 2019;11:882-891.

34. Li C, Hu Y, Huang J, et al. Comparison of robotic-assisted lobectomy with video-assisted thoracic surgery for stage IIB-IIIA non-small cell lung cancer. Transl Lung Cancer Res. 2019;8:820-828. 
35. Tong LP, Zheng XQ, Duan HT, et al.Clinical analysis for the short-term outcome of Da Vinci robotic-assisted left upper lobectomy for lung cancer.Chin J Clin Thorac Cardiovasc Surg.2020;27:183-189.

36. Huang ZG, Wu YZ, Liu YF, et al.Effect of da Vinci robot assisted thoracoscopic lobectomy on cardiopulmonary function and quality of life of patients with lung cancer. Department of Thoracic Surgery.2020;12:85-89.

37. Tian Y, Huang J, Lu PJ, et al.Perioperative outcomes of robot-assisted versus video-assisted right upper lobectomy in non-small cell lung cancer: A retrospective cohort study.Chin J Clin Thorac Cardiovasc Surg.2020;27:1134-1139.

38. Veluswamy RR, Whittaker-Brown SA, Mhango G, et al. Comparative Effectiveness of Robotic-Assisted Surgery for Resectable Lung Cancer in Older Patients. Chest. 2020;157:1313-1321.

39. Zhou Q, Huang J, Pan F, et al. Operative outcomes and long-term survival of robotic-assisted segmentectomy for stage IA lung cancer compared with video-assisted thoracoscopic segmentectomy. Transl Lung Cancer Res. 2020;9:306-315.

40. Haruki T, Kubouchi Y, Takagi Y, et al. Comparison of medium-term survival outcomes between robot-assisted thoracoscopic surgery and videoassisted thoracoscopic surgery in treating primary lung cancer. Gen Thorac Cardiovasc Surg. 2020;68:984-992.

41. Zhang Y, Chen C, Hu J, et al. Early outcomes of robotic versus thoracoscopic segmentectomy for early-stage lung cancer: A multi-institutional propensity score-matched analysis. J Thorac Cardiovasc Surg. 2020;160:1363-1372.

42. Qiu T, Zhao Y, Xuan Y, et al. Robotic sleeve lobectomy for centrally located non-small cell lung cancer: A propensity score-weighted comparison with thoracoscopic and open surgery. J Thorac Cardiovasc Surg. 2020;160:838-846.

43. Kneuertz PJ, D'Souza DM, Richardson M, et al. Long-Term Oncologic Outcomes After Robotic Lobectomy for Early-stage Non-Small-cell Lung Cancer Versus Video-assisted Thoracoscopic and Open Thoracotomy Approach. Clin Lung Cancer. 2020;21:214-224.

44. Alam N, Flores RM. Video-assisted thoracic surgery (VATS) lobectomy: the evidence base. JSLS. 2007;11:368-74.

45. Liang HR, Liang WH, Zhao L, et al. Robotic Versus Video-assisted Lobectomy/Segmentectomy for Lung Cancer: A Meta-analysis.Ann Surg. 2018;268:254-259.

46. Louie BE, Wilson JL, Kim S, et al. Comparison of video-assisted thoracoscopic surgery and robotic approaches for clinical stage I and stage II non-small cell lung cancer using the Society of Thoracic Surgeons Database. Ann Thorac Surg. 2016;102:917-24.

47. Adams RD, Bolton WD, Stephenson JE, et al. Initial multicenter community robotic lobectomy experience: comparisons to a national database. Ann Thorac Surg. 2014;97:1893-8.

48. Augustin F, Bodner J, Maier H, et al. Robotic-assisted minimally invasive vs. thoracoscopic lung lobectomy: comparison of perioperative results in a learning curve setting. Langenbecks Arch Surg. 2013;398:895-901.

49. Mahieu J, Rinieri P, Bubenheim M, et al. Robot-Assisted Thoracoscopic Surgery versus Video-Assisted Thoracoscopic Surgery for Lung Lobectomy: Can a Robotic Approach Improve Short-Term Outcomes and Operative Safety? Thorac Cardiovasc Surg. 2016;64:354-62.

50. Mungo B, Hooker CM, Ho-Janelle SY, et al. Robotic Versus Thoracoscopic Resection for Lung Cancer: Early Results of a New Robotic Program.J Laparoendosc Adv S. 2016;26:243-8.

51. Rajaram R, Mohanty S, Bentrem DJ, et al. Nationwide Assessment of Robotic Lobectomy for Non-Small Cell Lung Cancer.Ann Thorac Surg. 2017;103:1092-1100

52. Kilic A, Schuchert MJ, Pettiford BL, et al. Anatomic segmentectomy for stage $\otimes$ non-small cell lung cancer in the elderly. Ann Thorac Surg.2009;87:1662-1666.

53. Wilson JL, Louie BE, Cerfolio RJ, et al. The prevalence of nodal upstaging during robotic lung resection in early stage non-small cell lung cancer. Ann Thorac Surg.2014;97: 1901-1906.

54. Kneuertz PJ, Cheufou DH, D'Souza DM, et al. Propensity-score adjusted comparison of pathologic nodal upstaging by robotic, video-assisted thoracoscopic, and open lobectomy for non-small cell lung cancer. J Thorac Cardiovasc Surg. 2019; 158: 1457-1466.

55. Lee HS, Jang HJ. Thoracoscopic mediastinal lymph node dissection for lung cancer. Semin Thorac Cardiovasc Surg. 2012;24:131-41.

56. Louie BE, Farivar AS, Aye RW, et al. Early experience with robotic lung resection results in similar operative outcomes and morbidity when compared with matched video-assisted thoracoscopic surgery cases. Ann Thorac Surg. 2012;93: 1598-1604.

57. Wang PY, Xiong BH, Zeng YJ, et al. Meta-analysis of da Vinci robotic versus laparoscopic gastrectomy for gastric cancer. Chin J Gen Surg. $2017 ; 26: 412-424$.

58. Wei SY, Chen MH, Chen N, et al. Feasibility and safety of robot-assisted thoracic surgery for lung lobectomy in patients with non-small cell lung cancer: a systematic review and meta-analysis. World J Surg Oncol.2017;15:98.

59. Sienel W, Stremmel C, Kirschbaum A, et al. Frequency of local recurrence following segmentectomy of stage IA nonsmall cell lung cancer is influenced by segment localisation and width of resection margins-implications for patient selection for segmentectomy. Eur $\mathrm{J}$ Cardiothorac Surg. 2007;31:522-7

60. Swanson SJ. Video-assisted thoracic surgery segmentectomy: the future of surgery for lung cancer? Ann Thorac Surg. 2010;89:S2096-7.

\section{Figures}

Page $12 / 19$ 


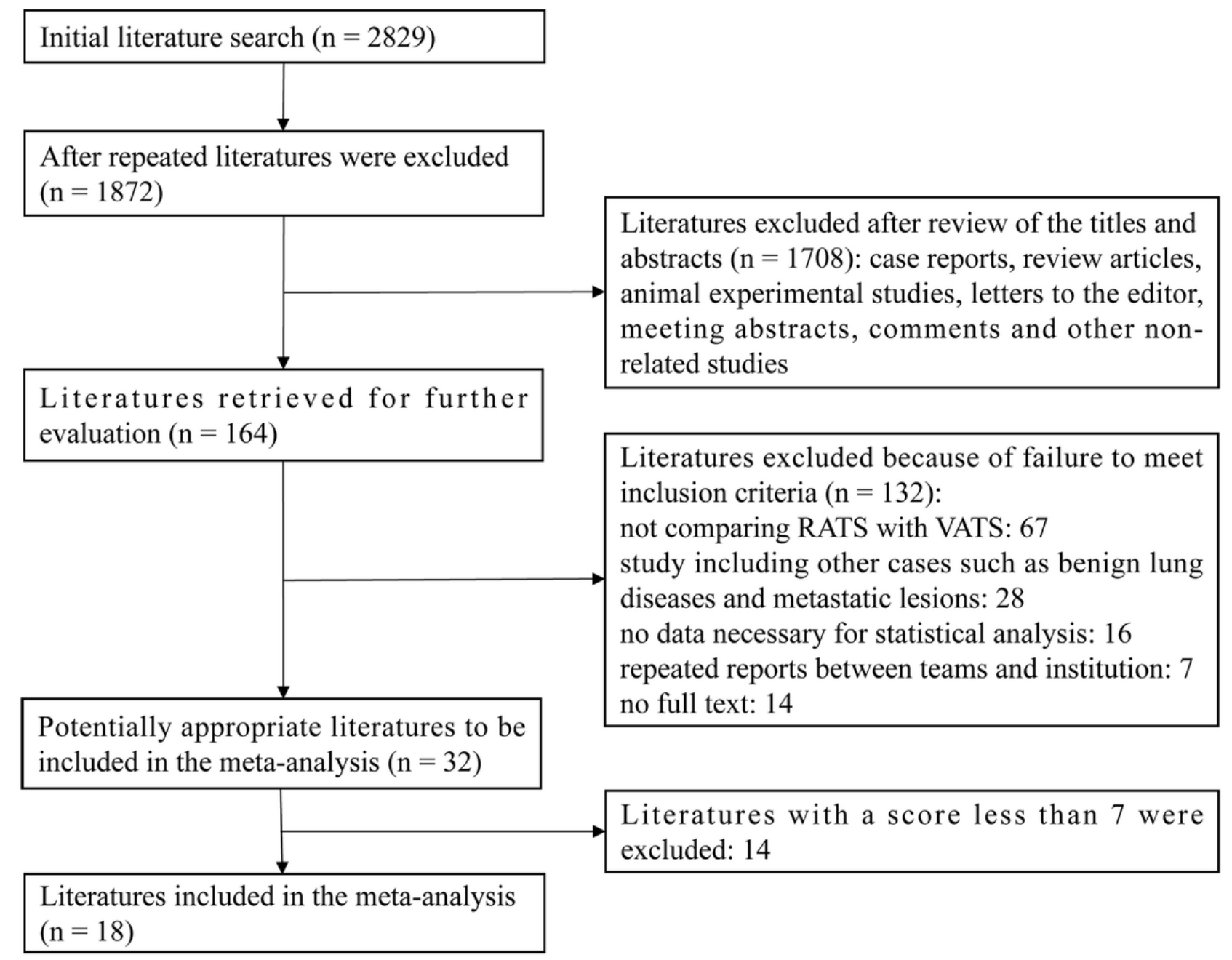

Figure 1

Flow chart of literature search strategies. 


\section{a}

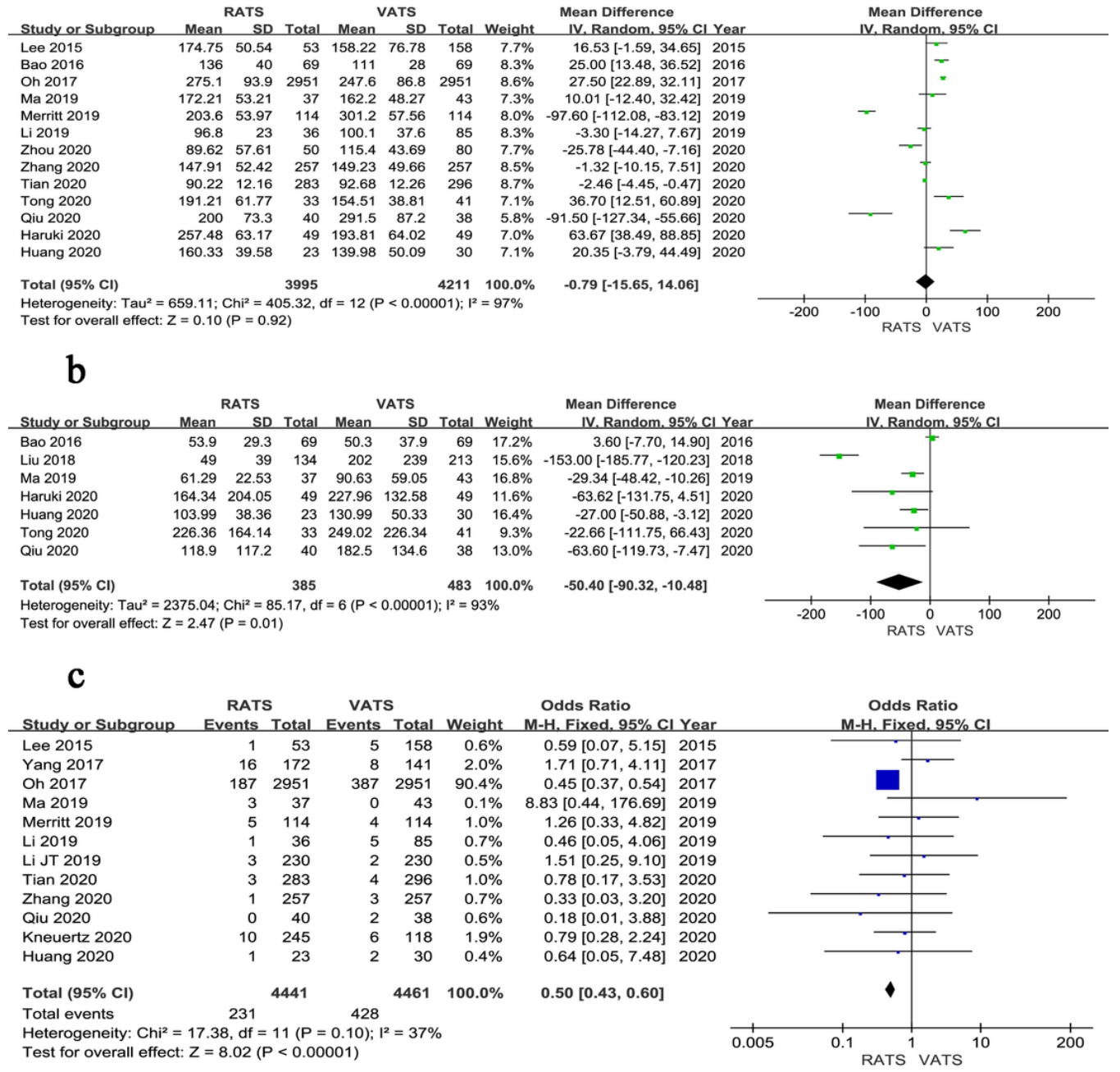

\section{Figure 2}

Forest plot of the meta-analysis for intraoperative parameters. a Operation time. b Estimated blood loss. c Conversion. 


\section{$\mathbf{a}$}

\begin{tabular}{|c|c|c|c|c|c|c|c|c|c|c|c|c|c|}
\hline \multirow[b]{2}{*}{ Study or Subgroup } & \multicolumn{3}{|c|}{ RATS } & \multicolumn{2}{|c|}{ VATS } & \multirow[b]{2}{*}{ Total } & \multirow[b]{2}{*}{ Weight } & \multirow{2}{*}{\multicolumn{2}{|c|}{$\begin{array}{l}\text { Mean Difference } \\
\text { IV. Random, } 95 \% \mathrm{Cl} \text { Year }\end{array}$}} & \multirow{2}{*}{\multicolumn{3}{|c|}{$\begin{array}{c}\text { Mean Difference } \\
\text { IV. Random. } 95 \% \mathrm{Cl}\end{array}$}} & \\
\hline & Mean & SD & Total & Mean & SD & & & & & & & & \\
\hline Bao 2016 & 7.4 & 1.6 & 69 & 7.6 & 1.7 & 69 & $11.2 \%$ & $-0.20[-0.75,0.35]$ & 2016 & & & & \\
\hline Yang 2017 & 4.5 & 2.35 & 172 & 3.25 & 2.05 & 141 & $11.9 \%$ & $1.25[0.76,1.74]$ & 2017 & & & & \\
\hline Liu 2018 & 5 & 2 & 134 & 4 & 2 & 213 & $12.5 \%$ & $1.00[0.57,1.43]$ & 2018 & & & & \\
\hline Li 2019 & 6.26 & 0.92 & 36 & 6 & 1.18 & 85 & $12.9 \%$ & $0.26[-0.13,0.65]$ & 2019 & & & & \\
\hline Li JT 2019 & 5.64 & 1.51 & 230 & 4.88 & 1.41 & 230 & $14.1 \%$ & $0.76[0.49,1.03]$ & 2019 & & & - & \\
\hline Huang 2020 & 9.5 & 0.86 & 23 & 9.09 & 1.06 & 30 & $11.5 \%$ & $0.41[-0.11,0.93]$ & 2020 & & & & \\
\hline Tian 2020 & 5.19 & 1.24 & 283 & 4.29 & 1.05 & 296 & $14.7 \%$ & $0.90[0.71,1.09]$ & 2020 & & & $\pi$ & \\
\hline Zhou 2020 & 1.32 & 1.6 & 50 & 1.91 & 1.45 & 80 & $11.2 \%$ & $-0.59[-1.14,-0.04]$ & 2020 & & & & \\
\hline Total $(95 \% \mathrm{Cl})$ & & & 997 & & & 1144 & $100.0 \%$ & $0.51[0.15,0.86]$ & & & & & \\
\hline $\begin{array}{l}\text { Heterogeneity: } \mathrm{Tau}^{2}= \\
\text { Test for overall effect }\end{array}$ & $\begin{array}{l}0.21 ; \mathrm{Cr} \\
=2.82\end{array}$ & $\begin{array}{l}\mathrm{i}^{2}=4 \\
(\mathrm{P}=\end{array}$ & $\begin{array}{l}.06, \mathrm{df} \\
.005)\end{array}$ & $=7(\mathrm{P}$ & $<0.000$ & 001); $\left.\right|^{2}$ & $=86 \%$ & & & -2 & $\begin{array}{ll}-1 & 0 \\
\text { RATS }\end{array}$ & $\begin{array}{r}1 \\
\text { VATS }\end{array}$ & 2 \\
\hline
\end{tabular}

b

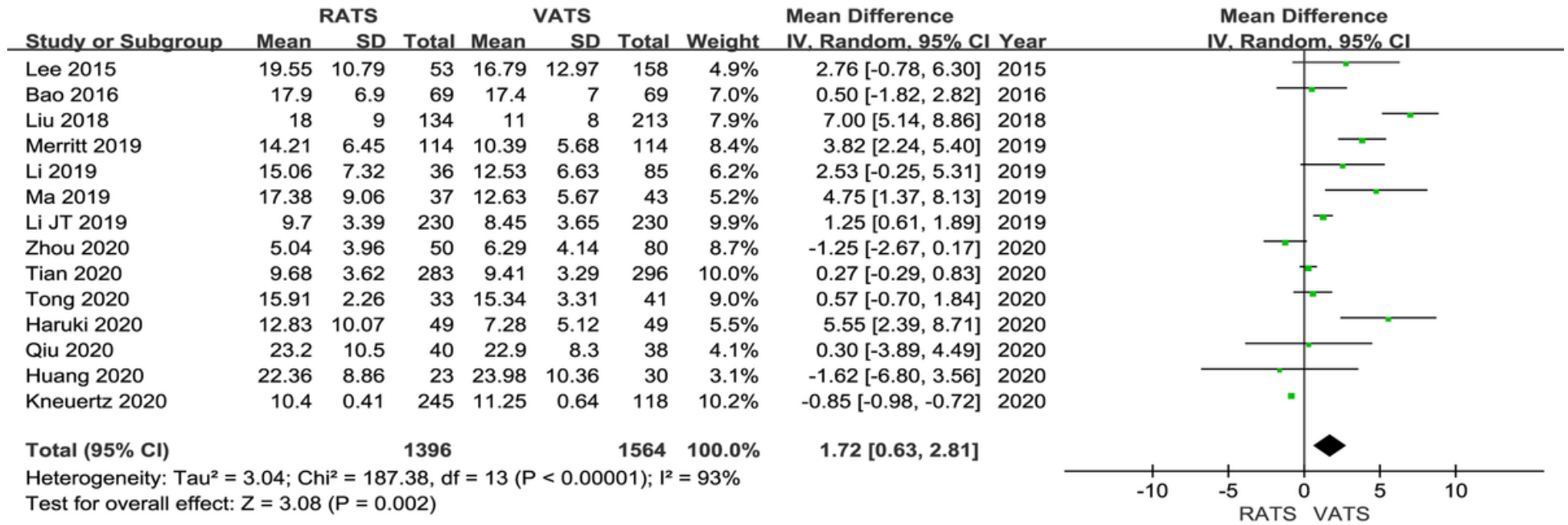

Figure 3

Forest plot of the meta-analysis for pathology details. a Number of dissected lymph node stations. b Number of dissected lymph nodes. 


\section{a}

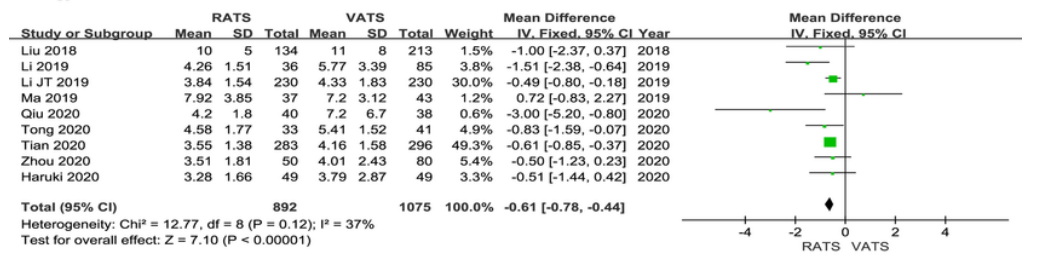

b

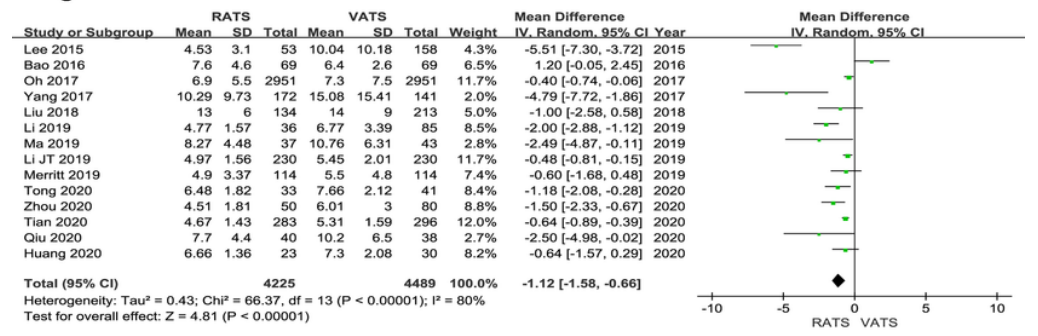

\section{c}

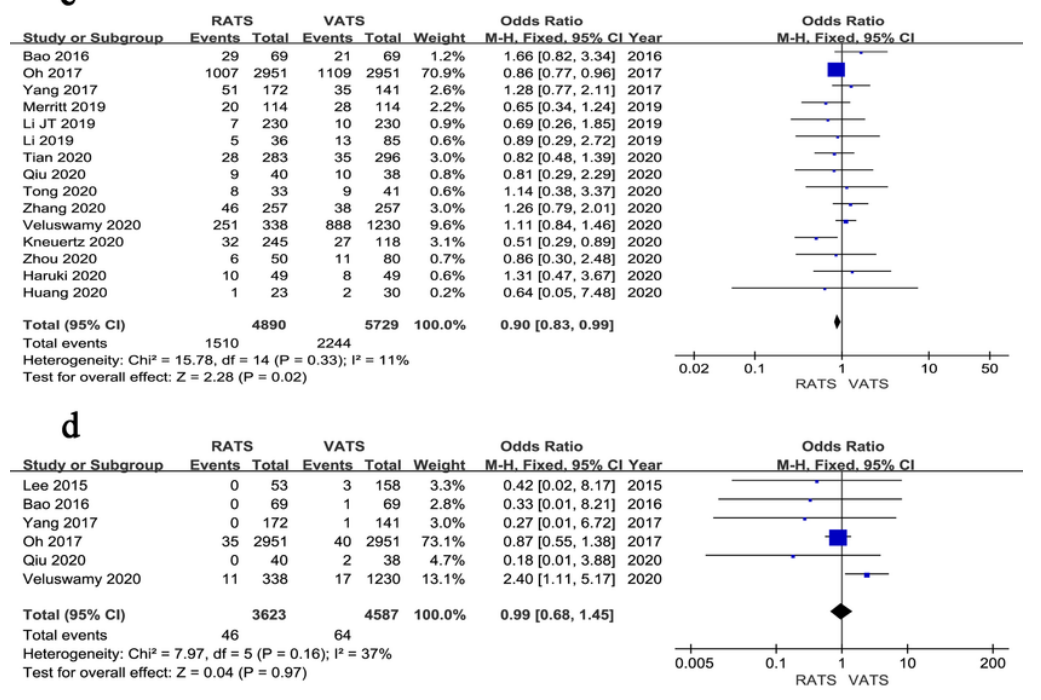

\section{Figure 4}

Forest plot of the meta-analysis for postoperative parameters. a Time of chest tube drainage. b Length of hospital stay. c Overall complications. D Mortality. 


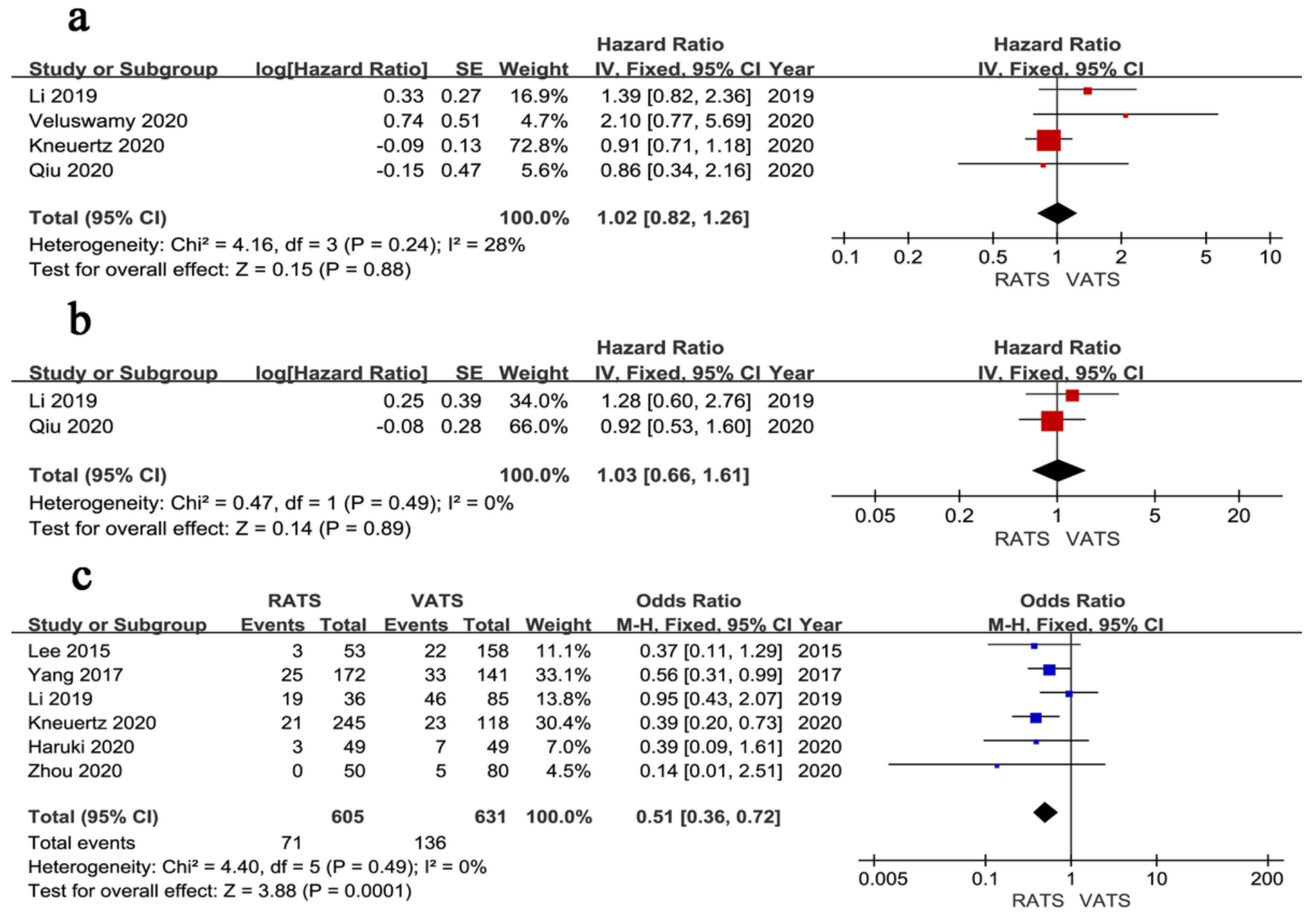

Figure 5

Forest plot of the meta-analysis for survival outcomes.a Overall survival.b Disease-free survival.c Recurrence rate. 


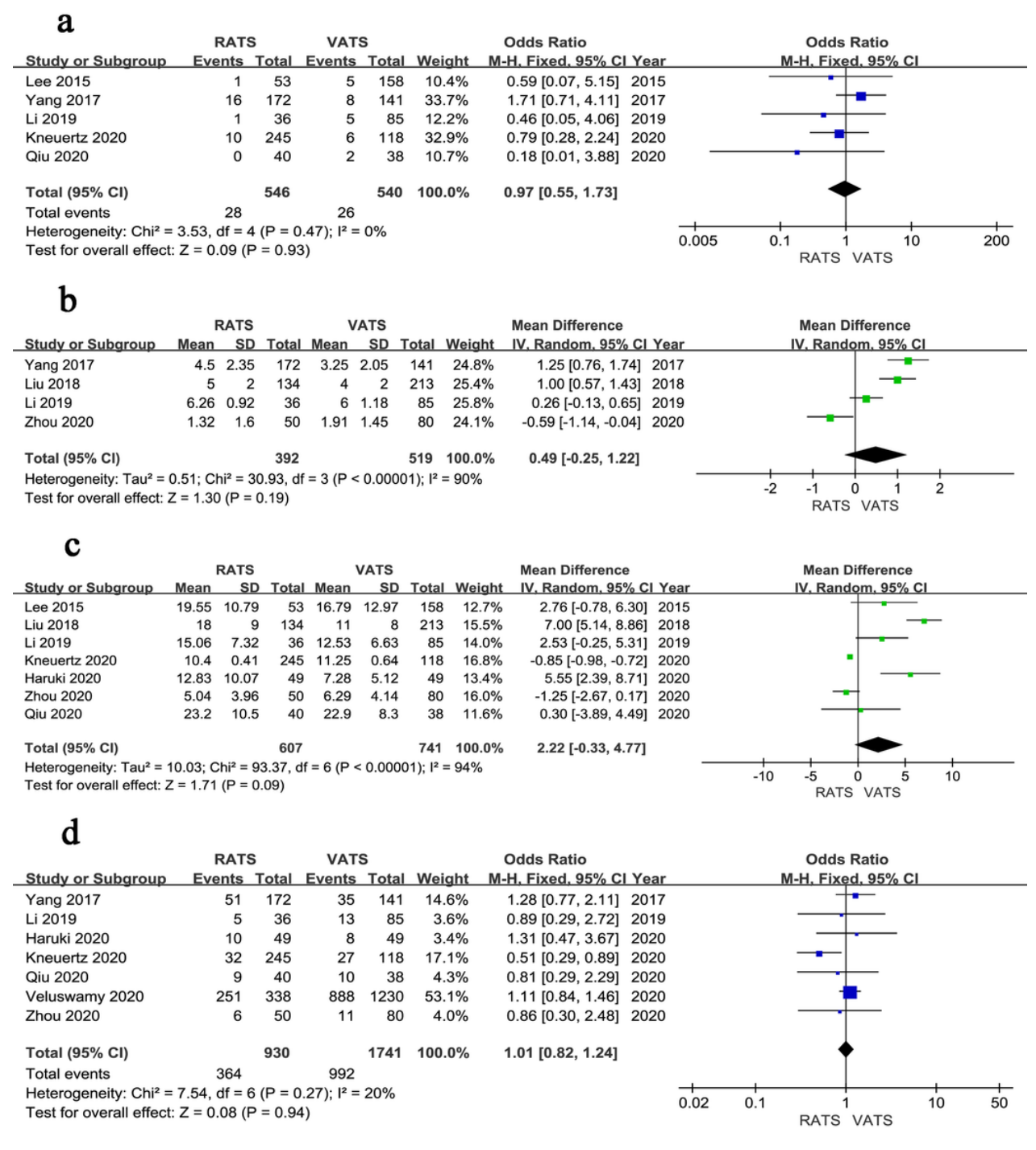

\section{Figure 6}

Forest plot of the sensitivity analysis. a Conversion. b Number of dissected lymph node stations. c Number of dissected lymph nodes. $d$ Overall complications. 


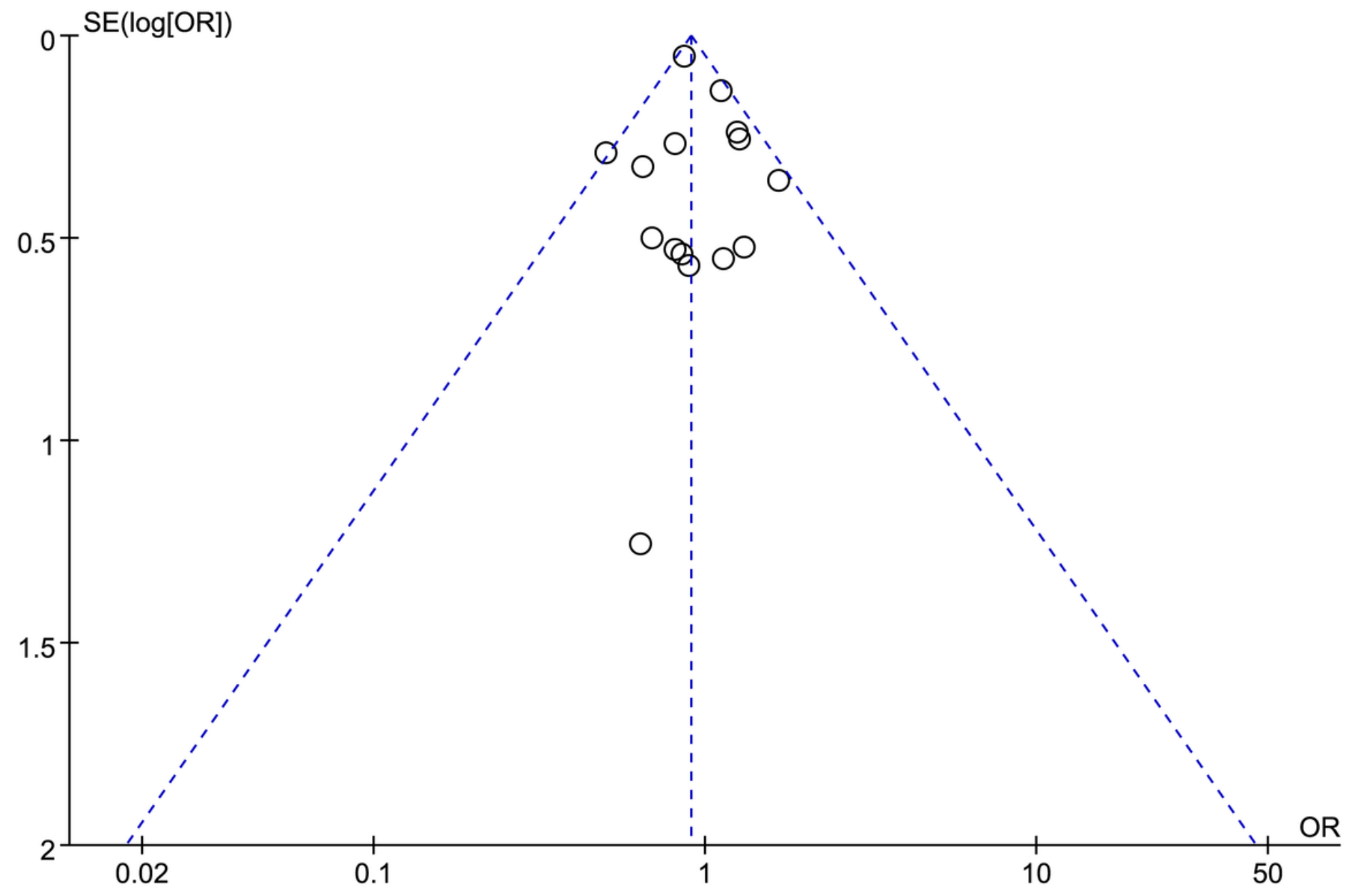

Figure 7

Funnel plot of the overall postoperative complications.

\section{Supplementary Files}

This is a list of supplementary files associated with this preprint. Click to download.

- FigureS1.docx

- Figures2.docx

- FigureS3.docx

- Figures4.docx

- FigureS5.docx

- PRISMAchecklist.doc 